\title{
Targeted disruption of the even-skipped gene, evx1, causes early postimplantation lethality of the mouse conceptus
}

\author{
Demetri D. Spyropoulos ${ }^{1}$ and Mario R. Capecchi ${ }^{2}$
}

Howard Hughes Medical Institute, Department of Human Genetics, University of Utah School of Medicine, Salt Lake City, Utah 84112 USA

\begin{abstract}
Implantation within the mammalian uterus elicits dramatic changes in the growth, differentiation, and morphogenesis of the conceptus. This process is interrupted in mice carrying a targeted disruption of the murine evx1 gene, a homolog of the Drosophila even-skipped (eve) gene. Upon implantation, presumptive evx $1^{-}$homozygotes elicit a decidual response, invade the uterine epithelium, and attach to the basement membrane between uterine stroma and epithelium, but fail to differentiate extraembryonic tissues or to form egg cylinders prior to resorption. Retrograde analysis of embryo genotypes demonstrates that homozygotes could be isolated as free-floating blastocysts but not as gastrulating egg cylinders. Homozygous mutant blastocysts appeared normal and, when grown in vitro, attach, proliferate, and form trophoblastic giant cells surrounding a growing inner cell mass before rapidly degenerating. In situ hybridization analysis demonstrates evx1 gene expression within the visceral endoderm after implantation and prior to gastrulation, at a time in which the mutant phenotype is first detected.
\end{abstract}

[Key Words: evx1; even-skipped; homeo box gene; conceptus; trophectoderm; visceral endoderm; egg cylinder; blastocyst outgrowth; postimplantation mutant]

Received May 26, 1994; revised version accepted July 1, 1994.

The placenta unites the mammalian embryo with the uterus and mediates metabolic exchange. This intimate association is established at implantation with the differentiation of five new extraembryonic cell types that form layers of cells between the postimplantation/pregastrulation embryo (the conceptus) and the uterus. Most mutant phenotypes affecting the conceptus have been considered to be defective in the proper development of extraembryonic tissues (Bennett 1975; McLaren 1976). It is the proximity of these tissues to the epiblast or embryonic ectoderm, the sole embryonic tissue of the conceptus, that seems to govern the rates of cell division, differentiation, and ultimately the morphogenesis of the conceptus (Gardner and Papaioannou 1975; Snow 1976; Hogan and Tilly 1981; Gardner 1983). A model outlining conceptus morphogenesis from an implanting blastocyst to a gastrulating egg cylinder has been described by Copp (1979; see Fig. 1). Proteolytic degradation of uterine epithelia, attachment of the hatched blastocyst to the basement membrane between uterine epithelia and stroma, and invasion of uterine stroma by differentiating trophoblastic giant cells occur at implantation /Strickland and

\footnotetext{
${ }^{1}$ Present address: Center for Molecular and Structural Biology, Hollings Cancer Center, Medical University of South Carolina, Charleston, South Carolina 29425-2213 USA

${ }^{2}$ Corresponding author.
}

Richards 1992|. Blastocyst attachment causes the growth of polar trophectoderm overlying the primitive ectoderm to be redirected from mural trophectoderm, which covers the blastocoel cavity, to extraembryonic ectoderm, which pushes the growing embryonic ectoderm into the blastocoel cavity and forms part of the egg cylinder (Fig. 1B). Concurrent with this process is the differentiation of primitive endoderm, which covers the blastocoel side of the primitive ectoderm, into visceral and then parietal endoderms. Visceral endoderm covers the growing egg cylinder producing microvilli, which mediate metabolic exchange; parietal endoderm covers the inner wall of the mural trophectoderm and forms the thick Reichert's membrane, which encapsulates the egg cylinder in the yolk sac cavity. Polar trophectoderm then also forms the ectoplacental cone, which grows in the opposite direction into the uterine crypt (Fig. 1C). Copp (1979) proposed that physical constraints imposed on the growing conceptus by the walls of the uterine crypt force the primitive ectoderm and extraembryonic ectoderm to grow into the blastocoel cavity toward the abembryonic pole forming the egg cylinder. Thus, the integrity of each extraembryonic tissue is crucial to the formation of the egg cylinder.

The two mouse genes $e v x 1$ and $e v x 2$ were isolated through sequence similarity to the homeo box of the Drosophila even-skipped gene (Bastian and Gruss 1990). 
Figure 1. Morphogenesis of the conceptus from blastocyst to egg cylinder (adapted from Copp 1979). (A) Prior to blastocyst implantation, the primitive endoderm just begins to differentiate into visceral endoderm covering the blastocoel side of the primitive ectoderm. An increase in mural trophectoderm cell number occurs by cell division within and migration away from the polar trophectoderm. (B) Attachment of the mural trophectoderm to the basement membrane between uterine stroma and epithelium causes migration of dividing polar trophectoderm to be redirected towards the embryonic ectoderm, pushing the embryonic ectoderm into the blastocoel cavity and forming the extraembryonic ectoderm. The mural trophectoderm differentiates into trophoblastic giant cells. The mitotic index of the embryonic ectoderm begins its dramatic increase, and differentiating visceral endoderm migrates over

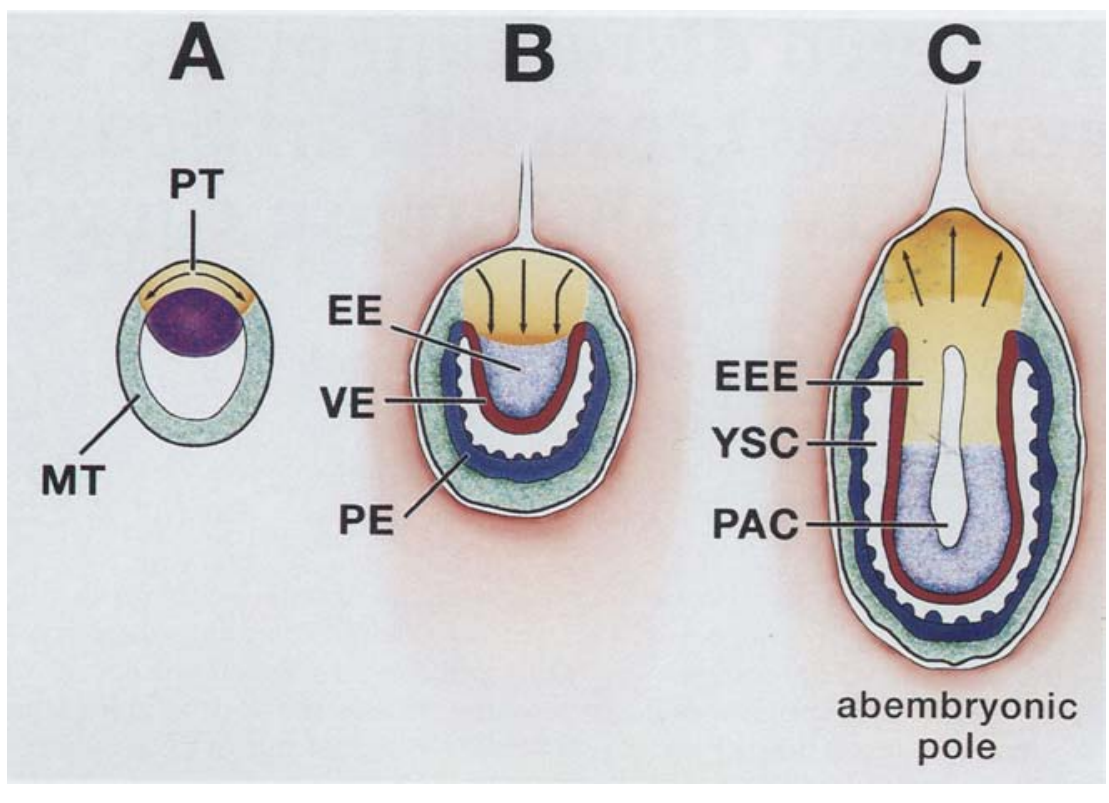
the inner surface of the blastocoel cavity forming parietal endoderm. At this stage, the evx1 gene function within visceral endoderm is proposed to be essential in the morphogenesis of the egg cylinder. $(C)$ Integrity of the yolk sac and the egg cylinder is established by the formation of Reichert's membrane by parietal endoderm and a basal lamina between embryonic ectoderm and visceral endoderm. Elongation of the egg cylinder within the yolk sac cavity becomes restricted and is accompanied by a redirection in the growth of polar trophectoderm toward the embryonic pole and the differentiation of the ectoplacental cone (orange). (MT) Mural trophectoderm; (PT) polar trophectoderm; (EE) embryonic ectoderm; (VE) visceral endoderm; (PE) parietal endoderm; (EEE) extraembryonic ectoderm; (YSC) yolk sac cavity; (PAC) proamniotic cavity. Purple in $A$ represents the ICM with primitive ectoderm and endoderm just beginning to be delineated.

$e v x 1$ and $e v x 2$ share extended similarity outside of their homeo domains and are closely linked to the $5^{\prime}$ end of the $\operatorname{Hox} A$ and $\operatorname{Hox} D$ gene clusters, respectively. RNA in situ hybridization studies show strong evx1 gene expression just prior to gastrulation within the cells of the embryonic ectoderm that give rise to the primitive streak, and later expression is seen within posterior neuroectoderm and the limb buds (Bastian and Gruss 1990; Dush and Martin 1992). No evx1 expression has been reported prior to embryonic day 6.25 (E6.25). Only low levels of $e v x 2$ expression were detected at any time during embryonic development.

In this paper we describe the phenotype of mice carrying a targeted disruption of the $e v x 1$ gene. Heterozygotes are viable, fertile, and normal in appearance. In contrast, homozygotes show a distinctly abnormal phenotype shortly after implantation in utero and outgrowth in vitro. In utero, extraembryonic tissues fail to differentiate, and the egg cylinder fails to form. Embryonic lethality occurs shortly after implantation, and resorption of the conceptus is initiated prior to gastrulation. In vitro, trophectodermal and inner cell mass (ICM) tissues proliferate after blastocyst attachment and outgrowth, but then both degenerate rapidly. These results combined with $e v x 1$ expression studies presented here suggest that $e v \times 1$ is produced within visceral endoderm and that this expression is critical to the differentiation and morphogenesis of the conceptus. The phenotype of evx $1^{-} / \mathrm{evxl} 1^{-}$mutants is compared with other peri-implantation mutants.

\section{Results}

Disruption of the evxl gene in mouse embryonic stem cells

Figure 2a shows the targeting vector used to disrupt, by homologous recombination, the evx1 gene within mouse embryonic stem (ES) cells (Capecchi 1989, 1994). The vector contains $10 \mathrm{~kb}$ of genomic DNA surrounding the evx1 gene. The MC1NeopA cassette (Thomas and Capecchi 1987) replaces a restriction fragment that codes for the first amino acid residues in the first helix of the homeo domain and continues through to intron 2 lOtting et al. 1988; Bastian and Gruss 1990). The deletion of helices 1, 2, and the first half of helix 3 from the homeo domain, as well as the exon 2 splice donor sequences, should render any potential mutant evx1 gene products nonfunctional with respect to DNA binding. Flanking evx1 genomic sequences on both sides are copies of the herpes simplex virus (HSV) thymidine kinase genes, TK1 and TK2 (Chisaka and Capecchi 1991).

The evx1 targeting vector was introduced into the CC1.2 ES cell line by electroporation (Deng and Capecchi 1992). Cells in which a homologous recombination event had occurred were enriched by positive-negative 


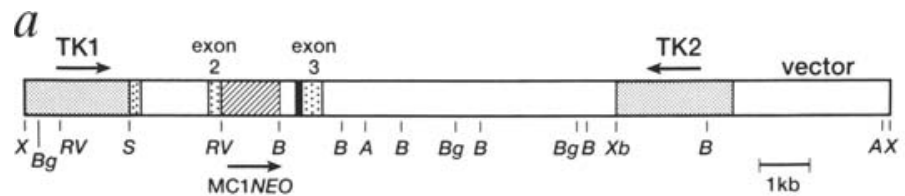

$b$
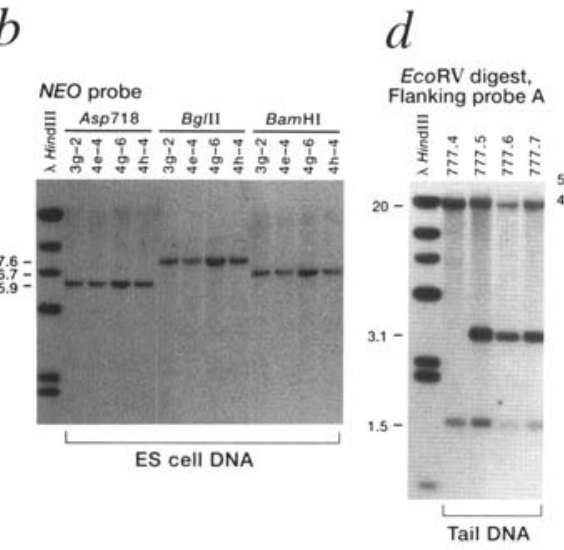

C

Wild-type ES cell line

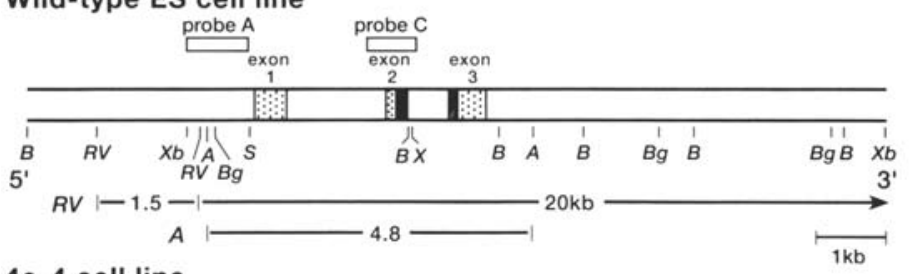

4 e- 4 cell line

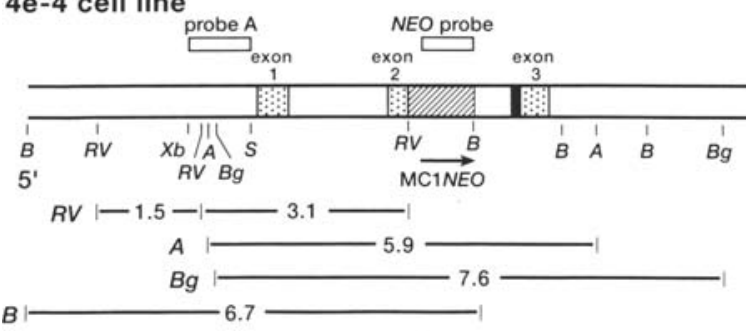

Asp718 digest, Internal probe $C$ $+1-\mathrm{X}+1-$ crosses
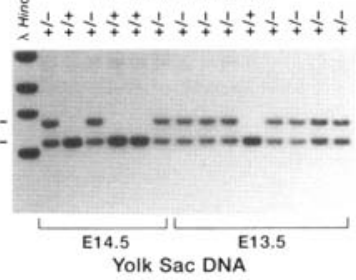

Asp718 digest, Internal probe C $+1-\mathrm{X}+1-$ crosses

$\frac{1}{+}+\frac{1}{+}+\frac{1}{+}+\frac{1}{+}+\frac{1}{+}$

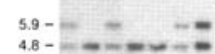

$4.8-2-m-\infty+0$

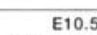

Yolk Sac DNA

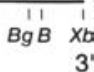

Figure 2. Southern transfer analysis of ES cell lines containing the homologous replacement of the evx1 gene with targeting vector sequences $(a, b, c)$ and genotyping of the progeny derived from chimera outcrosses and $e v \times 1^{-} / e v x 1^{+}$intercrosses $(d)$. (a) Structure of the targeting vector, $\mathrm{p} E v \times 1$ neo2TK, used to disrupt the evx1 gene in ES cells. The HSV TK1 and TK2 genes are in opposite orientations, and the MCINEOpA gene cassette is in the same orientation as the TKl and evx1 genes. $(b)$ Southern transfer analysis of DNA from the four targeted ES cell lines. The sizes of the DNA fragments are indicated in kilobases. DNA samples digested with $A s p 718, B g l I I$, and BamHI were hybridized with the NEO probe, a 768-bp EagI-BamHI fragment from the coding region of the neomycin phosphotransferase gene, present only in targeting vector sequences. Homologous recombinants were characterized by the appearance of single hybridizing DNA fragments of $5.9 \mathrm{~kb}$ for $A s p 718,7.6 \mathrm{~kb}$ for $B g I I I$, and $6.7 \mathrm{~kb}$ for BamHI. $\langle\mathrm{c}|$ Restriction maps of genomic DNA present in the parental $\mathrm{CC} 1.2$ cell line and the targeted $4 \mathrm{e}-4$ cell line that was used to generate the germ-line chimera number 777. (d) Genotyping, as determined by Southern transfer analysis, of 4-week-old agouti offspring from a cross between germ-line chimera 777 and C57BL/6J females (left), and 14.5- and 13.5-day-old embryos (top right), and 10.5-day-old embryos (bottom right) from $e v \times 1^{-} / \mathrm{evx} 1^{+}$ intercrosses. DNA digested with EcoRV was hybridized with flanking probe A, an 880-bp SmaI-Sall 5' evx1 genomic fragment not present in the targeting vector (left). DNA digested with $A s p 718$ was hybridized with internal probe $C$, a 670-bp PvulI-XhoI from evx1 exon 2 (right). Agouti offspring demonstrating a 3.1-kb hybridizing band $(d, l e f t)$ are heterozygous for the evx1-gene disruption. The progeny from the $e v \times 1^{-} / e v \times 1^{+}$intercrosses $(d$, right panels $)$ are all either wild-type, demonstrating a single 4.8 -kb hybridizing band, or heterozygous for the $e v \times 1^{-}$gene disruption, demonstrating both 5.9- and 4.8-kb hybridizing bands. No homozygotes for the $e v \times 1^{-}$gene disruption (demonstrating the $5.9-\mathrm{kb}$ band alone) were detected. (A) Asp718; (B) BamHI; (Bg) BglII; (RV) EcoRV; (X) XhoI; (Xb) XbaI; (S) Sall. (Solid boxes) Homeo box sequences; (hatched boxes) MC1NEOpA cassette; (stippled boxes) HSV TK1 and TK2 genes; (dotted boxes) evx1 exons. selection in medium containing G418 and FIAU (Mansour et al. 1988). Cell lines containing a disrupted evx1 allele were identified by Southern transfer analysis with a flanking probe derived from sequences outside the targeting vector (Fig. 2c, probe $A_{\text {; }}$ data not shown). Of 95 G418/FIAU resistant cell lines, the genomic DNA in four had undergone homologous recombination with the targeting vector (Figure $2 b, c$ ). Additional Southern transfer analyses with $e v \times 1$ and neo probes confirmed that all four cell lines contained the predicted replacement of one of the wild-type $e v x 1$ genes with sequences from the targeting vector (Fig. $2 \mathrm{~b}, \mathrm{c}$ ). Cell line $4 \mathrm{e}-4$ was used to generate chimeric males that transmitted the mutant allele to their progeny.
Embryonic lethality and resorption occur between implantation and gastrulation in $\mathrm{evx} 1^{-} / \mathrm{evx} 1^{-}$ mice

The progeny from $e v \times 1^{-} / e v \times 1^{+}$intercrosses did not include mice homozygous for the evx1 mutation, suggesting that embryonic lethality had occurred among homozygotes (Fig. 2d; Table 1). To determine the time of embryonic lethality, DNA was isolated from the yolk sacs of E10.5-15.5 embryos and from the egg cylinders of E6.5-7.5 embryos obtained from heterozygous intercrosses, and analyzed by Southern transfer and PCR, respectively (Fig. 2d, right panels; Fig. 3). The analyzed embryos from these intercrosses were found to be either 
Table 1. Genotypic analysis of $\mathrm{evx}^{-} / \mathrm{evx} 1^{+}$ intercross progeny

\begin{tabular}{lrrrr}
\hline & \multicolumn{3}{c}{ Genotype } & \\
\cline { 2 - 4 } DNA source & $+/-$ & $+/+$ & $-/-$ & Resorptions \\
\hline 4-Week old (tails) & 33 & 20 & 0 & - \\
E10.5-E15.5 (yolk sacs) & 24 & 14 & 0 & 14 \\
E6.5-E7.5 (egg cylinders) & 24 & 19 & 0 & $8^{\mathrm{a}}$ \\
$\quad$ Totals & 81 & 53 & 0 & \\
E3.5 (blastocysts) & 7 & 2 & 4 & - \\
E4.0TC5 (outgrowths) & 20 & 6 & $11^{\mathrm{c}}$ & - \\
$\quad$ Totals & 27 & 8 & 15 & \\
\hline
\end{tabular}

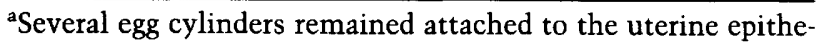
lium and were lost during dissection.

${ }^{b} \mathrm{E} 4.0$ blastocysts were cultured on coated or uncoated dishes in CMRL 1066 medium containing $1 \mathrm{~mm}$ sodium pyruvate, $1 \mathrm{~mm}$ L-glutamine, and $15 \%$ FCS for 5 days.

${ }^{\mathrm{c}}$ Degeneration and detachment of these blastocyst outgrowths sometimes required picking prior to tissue culture day 5 .

wild type or heterozygous for the mutation, showing either only the 148-bp wild-type PCR product or both the 148- and 263-bp heterozygous PCR products (Fig. 3B; Table 1). No evx1- homozygotes, having only the 263-bp PCR product, were detected (Table 1; Fig. 3B). An exact test of binomial proportions showed no significant deviation from a 2:1 (heterozygote/wild-type) ratio, indicating that $e v \times 1^{-}$homozygotes were not missed as a result of contamination of egg cylinders with maternal tissue. These results demonstrate that $e v \times 1^{-} / e v \times 1^{-}$embryos could not be isolated as early as gastrulation and suggest that embryonic lethality and resorption occurred earlier.

PCR analysis of DNA from E4.0 hatched blastocysts and blastocysts grown in vitro, however, demonstrates that $e v \times 1^{-}$homozygotes were viable prior to implantation (Fig. 3C; Table 1). evx1-/evx1- blastocysts appear indistinguishable from $e v \times 1^{-} / e v \times 1^{+}$and wild-type blastocysts (Figs. 4A and 5A). Taken together, results of this retrograde genotypic analysis suggest that the $e v \times 1^{-}$/ $e v \times 1^{-}$embryos were dying and being resorbed after the blastocyst stage but before gastrulation.

\section{Lethality occurs rapidly after attachment and outgrowth in $\mathrm{evx} 1^{-} / \mathrm{evxl}^{-}$blastocysts grown in vitro}

To better understand evx1-/evx1- lethality, E4.0 hatched blastocysts isolated from $e v \times 1^{-} / e v \times 1^{+}$intercrosses were grown in vitro, examined for growth abnormalities, and subsequently genotyped. By optimizing growth conditions, blastocysts grown in vitro develop to the egg cylinder stage and can even be taken to the 8 -somite stage (Gonda and Hsu 1980; Wu et al. 1981). The series of developmental changes that occur during this process have been clearly delineated by these investigators. Mutant homozygotes, heterozygotes, and wildtype embryos were indistinguishable as E4.0 hatched blastocysts, attached blastocysts, and lipid vesicle-containing attached blastocysts (Figs. 4A-C and 5A-C). Dif- ferent phenotypes first became apparent by 1.5 days in culture with the retraction and degeneration of trophoblastic giant cells after lipid vesicles began to disappear and as trophoblastic giant cell polytene nuclei became more distinct (Figs. 4D-F and 5D-F). Concomitantly, the degeneration of the ICM involves the rounding up and detachment of cells and is followed by cell death (Figs. $4 \mathrm{D}-\mathrm{F}$ and $5 \mathrm{D}-\mathrm{F}$ ). Interestingly, the relative rates of trophoblastic giant cell and ICM degeneration in evx1-/ evx $1^{-}$blastocyst outgrowths could be changed by altering in vitro growth conditions (data not shown). For example, evx1-/evx1- blastocysts grown on a mouse embryo fibroblast feeder layer demonstrated a delay in trophoblastic giant cell degeneration but exhibited no alterations in the degenerative changes observed in the ICM (data not shown). PCR analysis of the genotype of blastocysts grown in vitro showed that all of the evx1homozygotes and none of the heterozygotes nor wild-

A

Wild-type Evx1 sequence

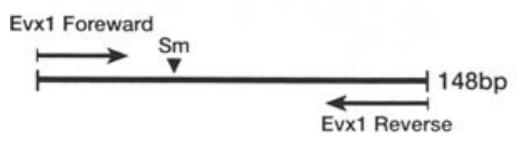

Evx1/pMC1NEO fusion sequence

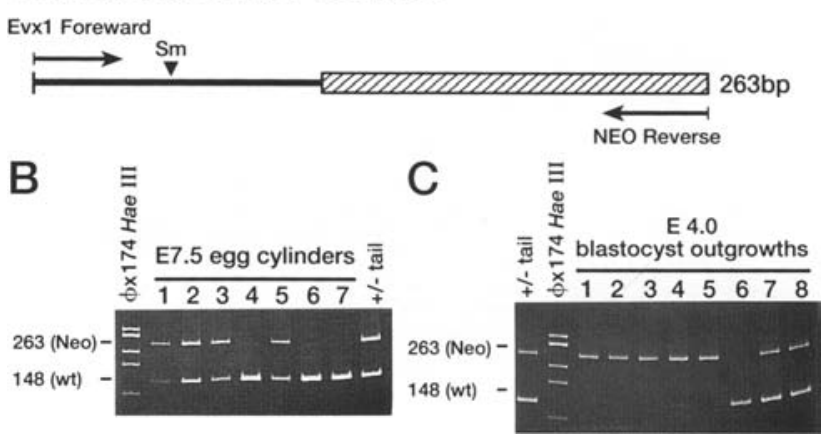

Figure 3. Genotypic analysis of evx1-/evx $1^{+}$intercross embryos using PCR. (A) Primers for genotypic analysis of wild-type and disrupted evx1 loci by PCR. DNA samples were subjected to genotypic analysis using a mixture of three primers for PCR: a forward $e v x 1$ primer, a reverse $e v x 1$ primer, and a reverse $N E O$ primer (see Materials and methods for sequences). PCR amplification of the wild-type evx1 allele by forward and reverse evx 1 primers produces a 148-bp DNA fragment (top sequence) while PCR amplification of the disrupted $e v \times 1^{-}$gene allele by the forward $e v x 1$ primer and reverse NEO primer produces a 263-bp DNA fragment (bottom sequence). (B) Genotypic analysis of E7.5 egg cylinders by PCR. Note the absence of $e v \times 1^{-} / \mathrm{evx} 1^{-}$ egg cylinders (lanes bearing the upper 263-bp band alone). $(C)$ Genotypic analysis of E4.0 blastocyst outgrowths by PCR. Blastocysts were flushed out of the uterus of an $e v x 1^{-} / e v \times 1^{+} \mathrm{fe}-$ male 4 days after a 2 -hr mating with an $e v x 1^{-} / e v x 1^{+}$male and grown in vitro for 3-5 days. Blastocyst outgrowths were picked and their DNAs PCR amplified. Note that the first five blastocysts picked all showed signs of degeneration and were all $e_{v \times 1} 1^{-} / e_{v x} 1^{-}$(demonstrating the upper 263-bp band alone). (Sm) Smal (hatched box) pMCINeopA sequences. 

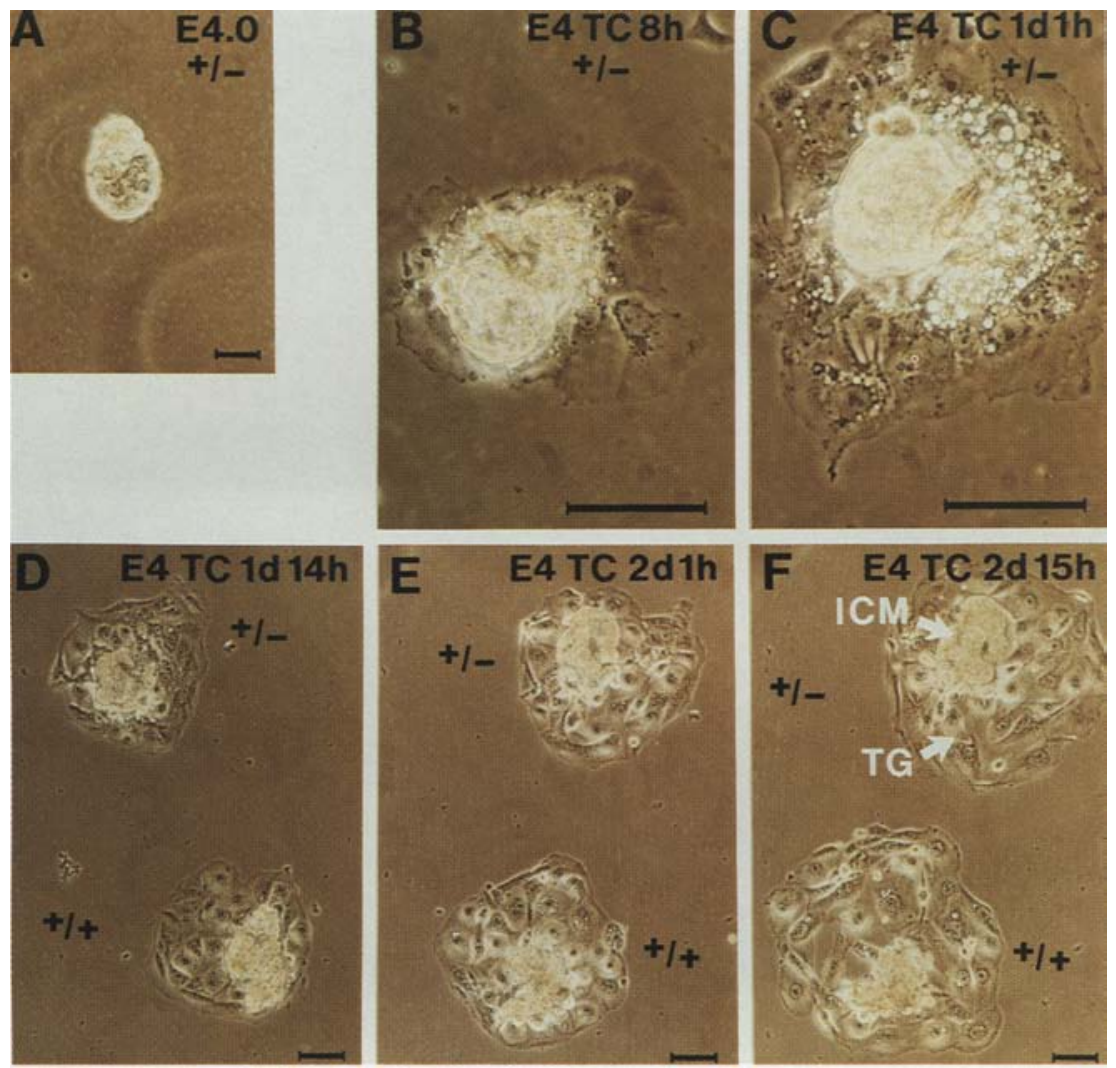

Figure 4. Outgrowth of wild-type $+1+$ and heterozygous $e v \times 1^{-} / e v x 1^{+} \mathrm{E} 4.0$ blastocysts in vitro. Blastocysts were flushed out of the uterus of an $e v \times 1^{-} / e v \times 1^{+} \mathrm{fe}$ male 4 days after a 2 -hr mating with an $e v x 1^{-} / e v x 1^{+}$male and grown in vitro as described in Materials and methods. $(A)$ E4.0 hatched $e v \times 1^{-} / e v \times 1^{+}$blastocyst; $|B|$ attached $e v \times 1^{-} / e v \times 1^{+}$blastocyst with minimal outgrowth; (C) evx $1^{-} / e v \times 1^{+}$ blastocyst outgrowth demonstrating lipid vesicles; $(D-F)+/+$ and $e v \times 1^{-} / e v \times 1^{+}$ blastocyst outgrowths demonstrating differentiated trophoblastic giant cells and growing egg cylinders. (ICM) Inner cell mass or growing egg cylinder; (TG) trophoblastic giant cell. Photographs were taken with a Diavert inverted microscope (Leitz). Bar, $100 \mu \mathrm{m}$. type blastocysts demonstrate this phenotype (Figs. 4 and 5 ; Table 1). A comparison of our results with those of Gonda and Hsu (1980) and Wu et al. (1981) suggests that embryonic lethality is occurring after the appearance of a distinct embryonic endoderm and prior to egg cylinder formation and the appearance of the proamniotic cavity. That is, degeneration occurs shortly after implantation (i.e., approximately at E5.0).

\section{Presumptive evx $1^{-}$mutant embryos fail to differentiate extraembryonic tissues and to undergo postimplantation morphogenesis}

Between implantation and gastrulation, the mouse conceptus grows 500 -fold in size, achieves a rate of cell division of 5-6 hr, forms an elongated egg cylinder, and gives rise to five extraembryonic cell types (Snow 1976; Gardner 1983). To document differences between wildtype and $e v \times 1^{-}$mutant embryos during this period, histological sections were made of wild-type and presumptive $e v \times 1^{-} / e v x 1^{-}$embryos growing in utero (Fig. 6 ; Table 2). Sections were prepared from decidual swellings in the uteri of wild-type or $e v \times 1^{-} / e v \times 1^{+}$intercrosses mated 4.5-6.5 days earlier. Following implantation (E4.5) and prior to the formation of an early egg cylinder within a yolk sac cavity (E5.0), abnormalities that distinguished $e v \times 1^{-} / e v \times 1^{-}$and normal concepti were not readily apparent (data not shown). One possible distinguishing feature was the absence of a thick, densely he- matoxylin-stained mural trophectoderm that surrounds the ICM and is adjacent to the basement membrane that lies between the uterine stroma and epithelium (Figs. $6 \mathrm{~A}, \mathrm{~F}$ and Table 2). A total of 11 of 11 wild-type embryos, produced by $\mathrm{B} 6$ intercross matings, demonstrated the densely, hematoxylin-staining mural trophectoderm. By E5.0, the presumptive wild-type and $e v \times 1^{-}$heterozygous embryos demonstrated significant growth and elongation of the egg cylinder, which contained both embryonic and extraembryonic ectoderms, clear differentiation of visceral and parietal endoderms, and formation of a distinct yolk sac cavity (Fig. 6B,C). In contrast, the presumptive $e v \times 1^{-} / e_{v \times} 1^{-}$embryos had invaded the uterine epithelium and attached to the basement membrane of the uterine stroma but did not show any signs of cellular growth, differentiation, or morphogenesis (Fig. $6 \mathrm{G}, \mathrm{H})$. By E5.5 the presumptive wild-type and evx $1^{-}$ heterozygous embryos had clearly distinct embryonic and extraembryonic ectoderm, a proamniotic cavity, and well-differentiated visceral endoderm and Reichert's membrane (Fig. 6D), whereas the presumptive evx $1^{-}$/ evx $1^{-}$embryos demonstrated slight growth but with a concomitant increase in cellular disorganization (Fig. 6I). By E6.0 the presumptive wild-type and $e v \times 1^{-}$heterozygous egg cylinders were almost ready for gastrulation, with egg cylinders that nearly fill the yolk sac cavity, an elongated proamniotic cavity, and a distinct exocoelemic cavity (Fig. 6E), whereas the presumptive $e v x 1^{-} / e v x 1^{-}$embryos demonstrated increasing cellular 
Figure 5. Outgrowth of homozygous $e v \times 1^{-} / e v x 1^{-} \mathrm{E} 4.0$ blastocysts in vitro. Blastocysts were flushed out of the uterus of an $e v x 1^{-} / e v x 1^{+}$female 4 days after a $2-h r$ mating with an $e v \times 1^{-} / e v \times 1^{+}$male and grown in vitro as described. $(A)$ E4.0 hatched $e v \times 1^{-} / e_{v X 1} 1^{-}$blastocyst; $(B)$ attached $e v x 1^{-} / e_{v x} 1^{-}$blastocyst with minimal outgrowth; $(C)$ evx $1^{-} / \mathrm{evxl}^{-}$blastocyst outgrowth demonstrating lipid vesicles; $(D-F)$ evx1-/evx1- blastocyst outgrowths demonstrating degeneration of trophoblastic giant cells and inner cell masses. (ICM) Inner cell mass; (TG) trophoblastic giant cell. Photographs were taken with a Diavert inverted microscope (Leitz). Bar, $100 \mu \mathrm{m}$.
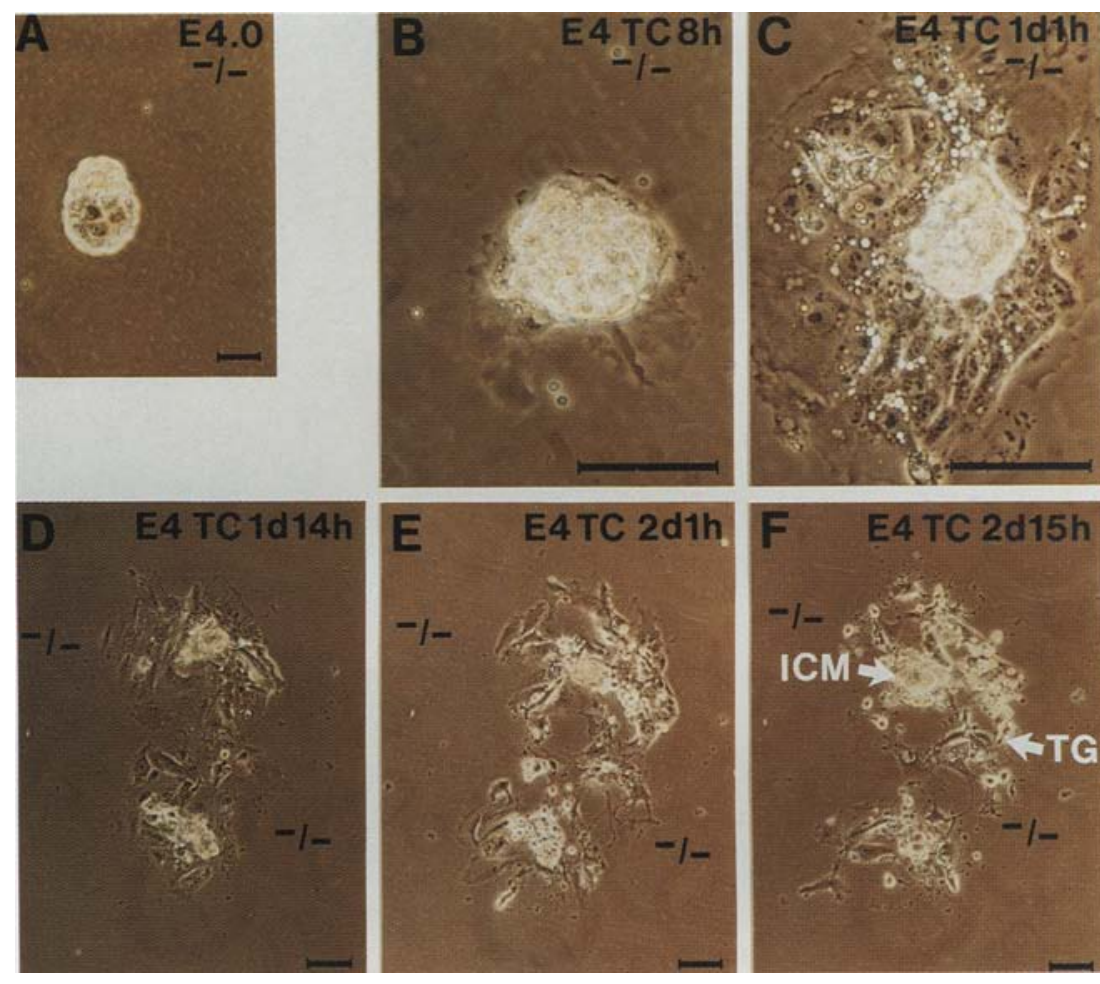

disorganization and pyknotic cells indicative of cell death (Fig. 6J). Resorption of presumptive $e v \times 1^{-} /$evx $1^{-}$ embryos was almost complete prior to the onset of gastrulation (data not shown), which is consistent with the genotypic analysis that demonstrated the absence of retrievable $e v \times 1^{-} / e v \times 1^{-}$gastrulating egg cylinders (E6.57.5; Table 1). Thus, the presumptive $e v \times 1^{-} / \mathrm{evx} 1^{-} \mathrm{em}$ bryos invade the uterine epithelium and attach to basement membrane of the uterine stroma properly but fail to undergo further cellular differentiation or morphogenesis. The proportion of embryos demonstrating the mutant phenotype fits the Mendelian prediction (Table 2).

evxl gene expression is first detected at E5.0 within the conceptus

evx1 expression has been detected at approximately E6.25 in the cells that will give rise to the primitive streak (Bastian and Gruss 1990; Dush and Martin 1992). The apparent early death of $e v \times 1^{-} / e v \times 1^{-}$embryos, as well as that of $e v \times 1^{-} / e v \times 1^{-}$blastocysts during in vitro culture, suggests that $e v x 1$ expression is critical prior to E6.25. To identify earlier evx1 expression, sections prepared from decidual swellings in the uteri of pregnancies generated from wild-type animals were hybridized with an $e v x 1$-specific antisense probe (Figs. 7-9). Sections of wild-type E6.5 embryos were included as positive controls (Fig. 7A,B). Low levels of $e v x 1$ gene expression were detected in egg cylinders as young as E5.0 (Fig. 7C-F) and in E5.5 and older egg cylinders (data not shown) but not within hatched and attached blastocysts (Fig. 7G,H). Spe- cific hybridization in E5.0 embryos was more easily detected in sections through the surface of egg cylinders than in sections through their centers /which demonstrated low levels of expression around the egg cylinder's outer periphery), suggesting that the evx1 gene was expressed within visceral endoderm during this period (Figs. 7C-F and 8). Similar specific hybridization patterns were detected at E5.0 and later in normal embryos derived from $e v x 1^{-} / e v x 1^{+}$intercross matings (data not shown) but were not observed in abnormal presumptive $e v \times 1^{-} / e v \times 1^{-}$embryos (Fig. 9A-F). As mentioned in the previous section, it was difficult to identify presumptive $e v \times 1^{-} / e v \times 1^{-}$concepti between implantation (E4.5) and the formation of a yolk sac cavity (approximately E5.0). Specific evx1 gene expression was not observed in these earlier concepti (Figs. 7G,H and 9E,F), nor was it observed within other cell types such as the trophoblastic giant cells. These in situ hybridization results suggest that $e v \times 1^{-} / e v \times 1^{-}$lethality occurs at the onset of detectable evx1 gene expression (approximately E5.0) and that lethality is the result of a defect in the developing visceral endoderm.

\section{Discussion}

The evx1- homozygous blastocyst appears normal, hatches, invades the uterine epithelium, and attaches to the basement membrane that lies between the uterine stroma and epithelium. The $e v \times 1^{-}$mutant phenotype is not apparent until after these steps of implantation. After implantation but prior to the formation of an egg 


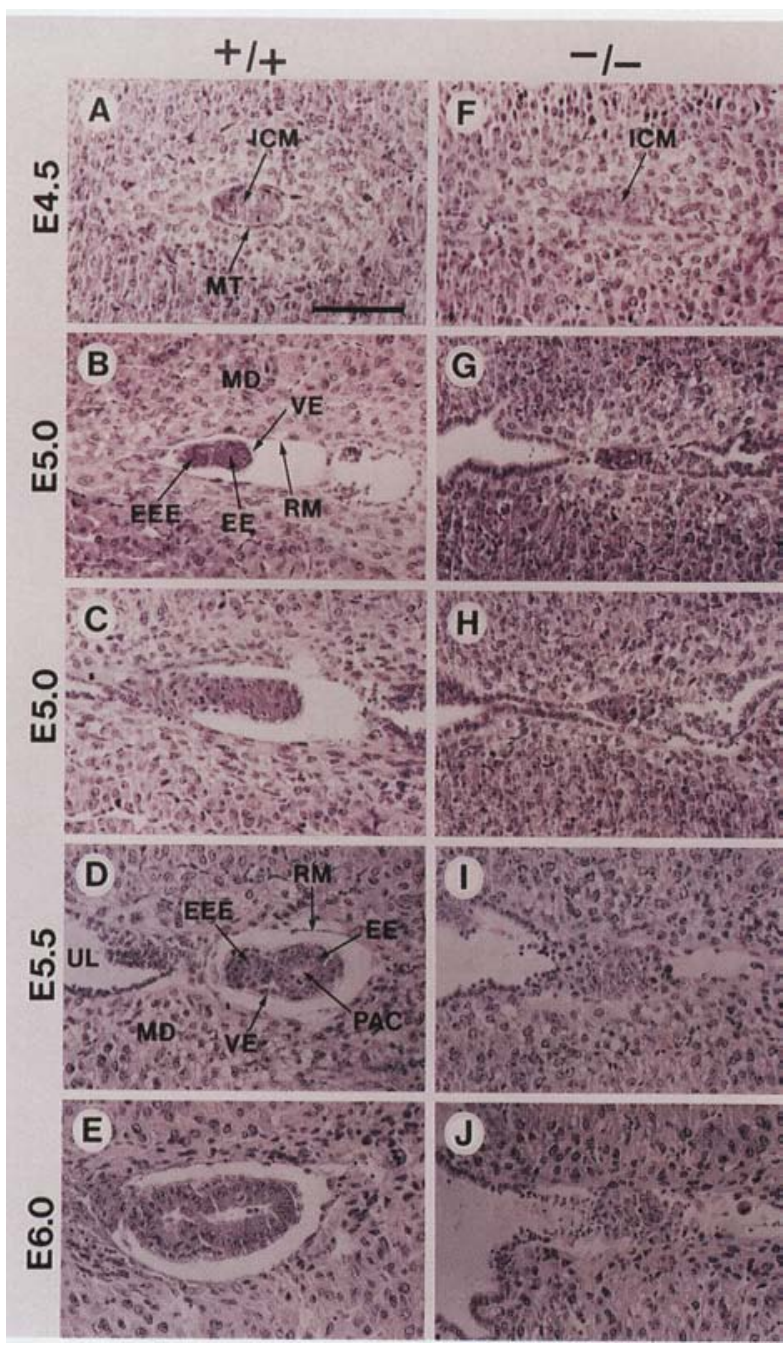

Figure 6. Histological sections of wild-type and presumptive $e v \times 1^{-} / e v x 1^{-}$embryos grown in utero. The uteri of $\mathrm{C} 57 \mathrm{BL} / 6 \mathrm{~J}$ or $e v \times 1^{-} / e v x 1^{+}$females were isolated 4.5-6 days after 2-hr intercross matings, and $8-\mu \mathrm{m}$ sections were prepared as described in Materials and methods. All uterine decidua were sectioned in transverse according to the nomenclature of Smith (1985), and the mesometrial/anti-mesometrial axis is left to right. $(A-E)$ C57BL/6J wild-type egg cylinders; $(F-I)$ presumptive evx1-) evx1- embryos. $(A, F)$ E4.5 embryo; $(B, G)$ E5.0 embryos; $\{C, H\rangle$ a more developed E5.0 egg cylinder and a mutant embryo; $\{D, I)$ E5.5 egg cylinder and mutant embryo (note the appearance of the proamniotic cavity and the clearly differentiated embryonic and extraembryonic ectoderms in $D)_{;}(E, /)$ pregastrulation E6.0 egg cylinder and degenerating mutant embryo. (EE) Embryonic ectoderm; (EEE) extra-embryonic ectoderm; (ICM) inner cell mass; (MD) maternal decidua; (MT) mural trophectoderm; (PAC) proamniotic cavity; (RM) Reichert's membrane; (UL) uterine lumen; (PVE) visceral endoderm. Bar, $100 \mu \mathrm{m}$.

cylinder, wild-type concepti have a thick, densely hematoxylin-stained layer of mural trophectoderm that separates the inner cell mass from maternal stroma (Fig. 6A). This may constitute the first phenotypic difference between mutant and wild-type concepti because this dis- tinct layer of mural trophectoderm is absent in presumptive $e v \times 1^{-} / e v \times 1^{-}$concepti (Fig. 6F). This in utero difference is consistent with in vitro results demonstrating the rapid degeneration of trophoblastic giant cells in evx $1^{-}$/evx $1^{-}$blastocyst outgrowths (Fig. 5). Subsequent differences between $e v \times 1^{-}$mutant and wild-type concepti are more obvious, especially those involving the lack of formation of Reichert's membrane by parietal endoderm and of a yolk sac cavity by visceral and parietal endoderms.

The absence of distinct embryonic and extraembryonic tissues in putative $e v \times 1^{-} / e v \times 1^{-}$embryos (Fig. 6F$\mathrm{Jl}$ and the rapid degeneration of trophectoderm and ICM in outgrowths of $e v \times 1^{-} / e v \times 1^{-}$blastocysts (Fig. 5) distinguishes this mutant from all other classes of periimplantation mutants. The $t^{\circ}$ (Bennett 1975; GluecksohnSchoenheimer 1940) and fug1 (DeGregori et al. 1994) mutants seem to be the closest to the $e v \times 1^{-}$mutant in terms of timing and the high degree of disorganization within the egg cylinder, even though they do form twolayer egg cylinders with yolk sac cavities, and outgrowths of $t^{6} / t^{6}$ blastocysts (an allele comparable to $t^{\circ}$; Erickson and Pedersen 1975) produce defective ICMs. Mov 34 (Soriano et al. 1987) is also similar to the $e v x 1^{-}$ mutant in terms of timing, but the mutation has not been fully described. Unlike the $e v \times 1^{-}$mutant, the survival of early implantation-defective mutants $t^{w 73}$ (Bennett 1975; Spiegelman et al. 1976) and lethal yellow $\left(A^{y}\right.$; Eaton and Green 1963; Papaioannou and Gardner 1979; Michaud et al. 1993) is determined by the degree of attachment between trophectoderm and maternal decidua, and well attached escapers form two-layer egg cylinders containing yolk sac and proamniotic cavities prior to degeneration. Also, $t^{w 73} / t^{w 73}$ blastocyst outgrowths appear normal (Axelrod 1985). In the class of early postimplantation mutants, velvet coat (Ve; McLaren 1976; Rossant and Viih 1981), blind (Bld; McLaren 1976; Vankin and

Table 2. Phenotypic analysis of uterine sections of evx $1^{-} / \mathrm{evx} 1^{+}$intercross embryos

\begin{tabular}{lcccc}
\hline \multirow{2}{*}{$\begin{array}{l}\text { Tissue source } \\
\text { (embryos) }^{\mathrm{a}}\end{array}$} & Decidua & Concepti & mutant & wild type \\
\cline { 4 - 5 } & 13 & 13 & 6 & 7 \\
E5.0 & 16 & $16^{\mathrm{d}}$ & 2 & $13^{\mathrm{e}}$ \\
E5.5 & 17 & 17 & 5 & 12 \\
E6.25 & 7 & 7 & 3 & 4 \\
E6.375 & 53 & 53 & 16 & $36^{\mathrm{f}}$ \\
\hline Totals & & &
\end{tabular}

${ }^{a}$ Mice were mated for $2 \mathrm{hr}$ early in the morning during the light cycle and separated, and females were checked for plugs.

bPhenotype was determined by visual inspection of hematoxylin- and eosin-stained sections.

${ }^{c}$ All of the wild-type and none of the mutant embryos showed densely, hematoxylin-staining mural trophectoderm.

${ }^{\mathrm{d}}$ One deciduum was empty and one contained two embryos.

eThe phenotype of one conceptus was not wild type but was distinct from the other mutants.

${ }^{\mathrm{f}} \mathrm{Chi}^{2}$ (1 d.f. $)=0.9231, P=0.3367,95 \%$ confidence range $=$ $0.1823-0.4331$. 


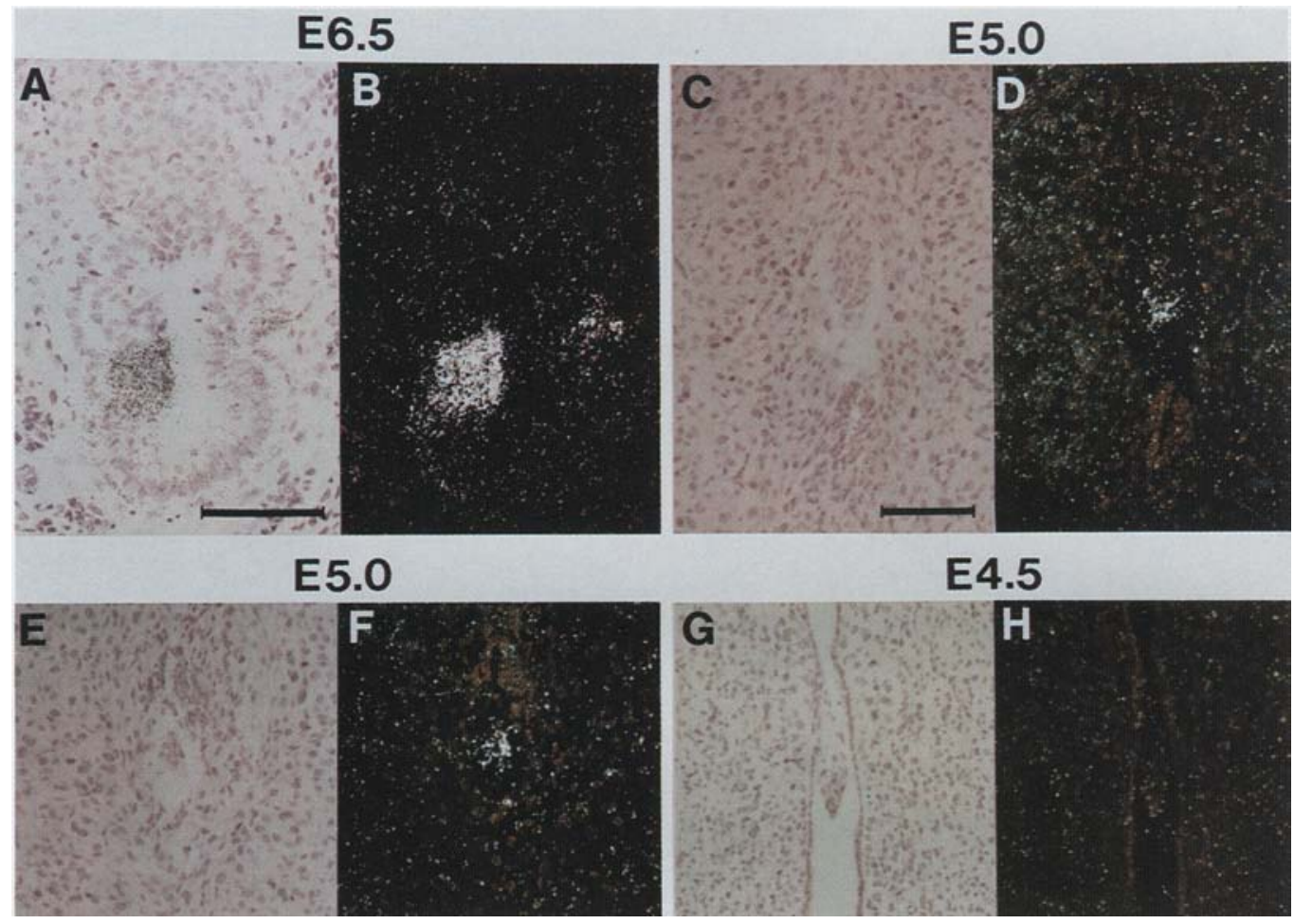

Figure 7. In situ hybridization of wild-type embryos in uterine sections. The uteri of C57BL/6 females were isolated 4.5-6.5 days after a 2-hr mating with $\mathrm{C} 57 \mathrm{BL} / 6 \mathrm{~J}$ males, and $8-\mu \mathrm{m}$ sections were prepared for in situ hybridization as described in Materials and methods. $\{A, B)$ Gastrulating E6.5 embryo; $(C, D)$ paramedial section of an E5.0 embryo; $(E, F)$ paramedial section of a less developed E5.0 embryo; $\{G, H)$ hatched blastocyst within the uterus. $(A, C, E, G)$ bright-field images; $(B, D, F, H)$ dark-field images. Hybridization with the evx1 sense strand was included as a negative control, demonstrating no specific hybridization at any of the stages studied (data not shown). Bar, $100 \mu \mathrm{m}$.

Caspari 1979), and $c^{6 H}$ (Lewis et al. 1976) demonstrate the best tissue differentiation, even though they produce morphologically abnormal egg cylinders. As with $t^{6} / t^{6}$ blastocysts, outgrowth of $V e / \mathrm{Ve}$ blastocysts produce poorly developed ICMs. Thus, the $e v \times 1^{-}$mutant appears to be more extreme than the previously described periimplantation, pregastrula mutants.

Perturbation of blastocyst outgrowth in vitro by exposing blastocysts to X-ray and ultraviolet irradiation (Rowinski et al. 1975), [ $\left.{ }^{3} \mathrm{H}\right]$ thymidine (Snow 1973), 5-bromodeoxyuridine (Pedersen and Spindle 1976), cytosine arabinoside (Sherman and Atienza 1975), inhibitors of RNA synthesis (cordycepin, actinomycin D, $\alpha$-amanitin; Golbus et al. 1973; Rowinski et al. 1975), and inhibitors of protein synthesis (cyclohexamide; Rowinski et al. 1975) in each case interferes with the development of the ICM but has no effect on the trophoblastic giant cells. This is interesting considering that the trophoblastic giant cells in $e v \times 1^{-} / e v \times 1^{-}$blastocyst outgrowths form and then rapidly degenerate in $<2$ days when grown in standard culture conditions. We have only seen this characteristic trophectodermal degeneration in wild-type blastocysts when they were cultured in the absence of serum (data not shown).

The failure to form distinct embryonic and extraem- bryonic tissues in putative $e v \times 1^{-} / e v x 1^{-}$embryos (Fig. $6 \mathrm{~F}-\mathrm{J}$ ), the rapid degeneration of trophectoderm in outgrowths of $e v \times 1^{-} / e v \times 1^{-}$blastocysts (Fig. 5), and the detection of $e v \times 1$ gene expression within the visceral endoderm (Fig. 8) suggests that the $e v \times 1^{-}$mutation has perturbed communication between embryonic and extraembryonic tissues critical to their further differentiation and maintenance. That is, assuming that the evx1 gene is not expressed at very low levels in other tissues, evx1 function in visceral endoderm is controlling the morphogenesis of embryonic ectoderm, parietal endoderm, and mural trophectoderm. Studies of chimeric embryos have demonstrated that cell to cell interactions are critical in embryonic/extraembryonic tissue differentiation (Snow 1976; Hogan and Tilly 1981; Gardner 1983), suggesting that a breakdown in communication between embryonic ectoderm and visceral endoderm would more than likely produce an abnormal egg cylinder (Bennett 1975). That visceral/parietal endoderm cell-to-cell interactions are critical in normal postimplantation development is supported by studies involving the in vitro differentiation of F9 embryonal teratocarcinoma cells (Casanova and Grabel 1988). A breakdown in communication between visceral and parietal endoderms could result in the loss of a distinct yolk sac cavity. Alterna- 

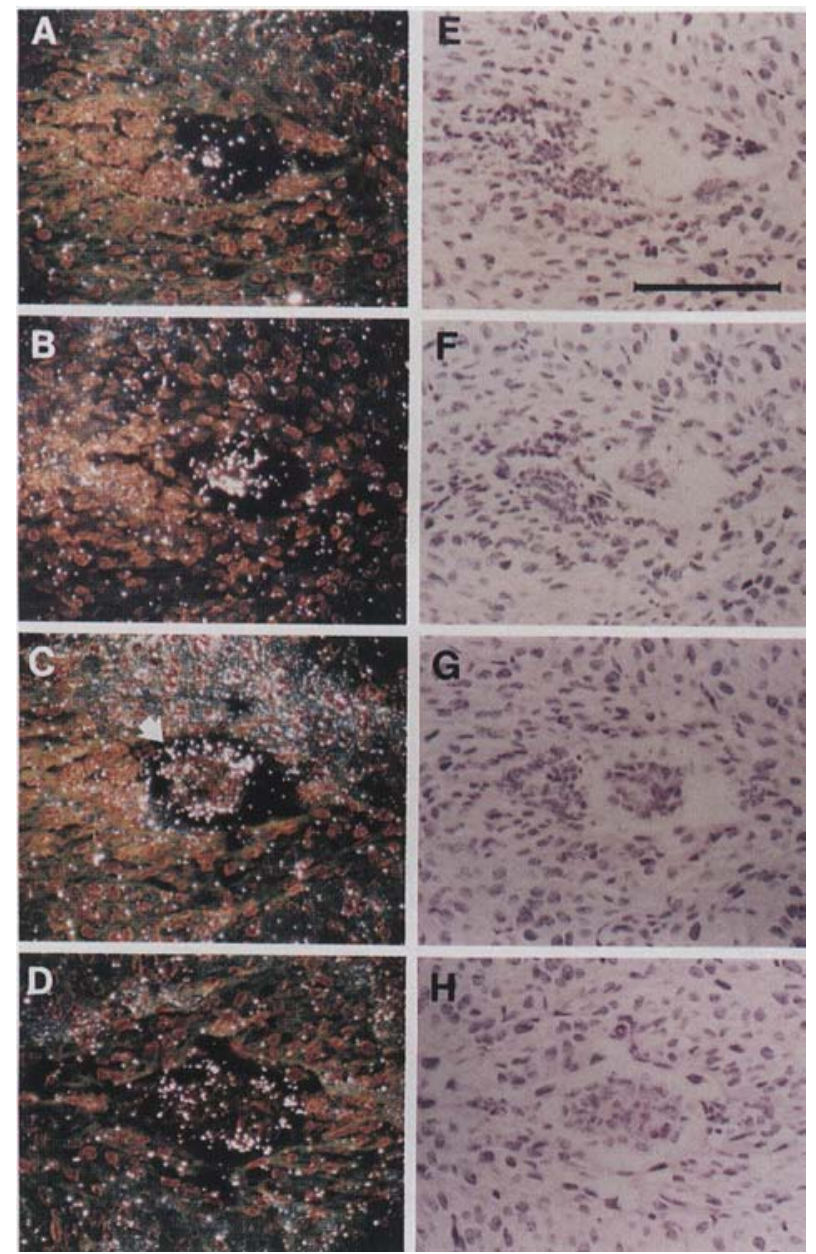

Figure 8. In situ hybridization of serial uterine sections of a wild-type E5.0 embryo. The uterus of a C57BL/6J female was isolated 5 days after a $2-\mathrm{hr}$ mating with a $\mathrm{C} 57 \mathrm{BL} / 6 \mathrm{~J}$ male, and $8-\mu \mathrm{m}$ sections were prepared for in situ hybridization with an evX1 antisense probe as described in Materials and methods. $(A-D)$ Dark-field images; $(E-H)$ bright-field images. $(A, E)$ First sagittal section through the surface of an E5.0 egg cylinder; $(B, F)$ third section through the E5.0 embryo; $(C, G)$ fifth section through the E5.0 embryo; $(D, H)$ seventh section through the E5.0 embryo. Note that evx1 expression is at first concentrated within the center of sections through the surface of the egg cylinder $(A, B, E, F)$ and then moves to the outer periphery of the egg cylinder (arrow) in sections that bisect the egg cylinder $|C, D, G, H|$. This pattern is consistent with expression of evx1 within the visceral endoderm. The mesometrial/antimesometrial axis is right to left. Hybridization with the evx1 sense strand was included as a negative control, demonstrating no specific hybridization (data not shown). Bar, $100 \mu \mathrm{m}$.

tively, differentiation of parietal endoderm from visceral endoderm (Gardner 1983) may be defective in $e v \times 1^{-} \mathrm{mu}-$ tant embryos considering that prior to visceral/parietal endoderm differentiation, wild-type and $e v \times 1^{-} / e v \times 1^{-}$ embryos are indistinguishable (Figs. 4 and 5). The control of mural trophectoderm differentiation via $e v x 1$ function in the visceral endoderm is more difficult to explain even though it constitutes a distinct feature of the $e v \times 1^{-} /$ $e v \times 1^{-}$mutant phenotype.

What alteration(s) in gene expression within visceral endoderm leads to the disorganization of tissues in $e v \times 1^{-} / e v \times 1^{-}$embryos? evx1 protein has been implicated in the regulation of cell and substrate adhesion molecule gene expression, specifically that of the extracellular matrix glycoprotein tenascin (Jones et al. 1992; Edelman and Jones 1993). Mice homozygous for a disruption of the tenascin gene develop normally (Saga et al. 1992). Although tenascin has been shown to be induced at the site of implantation in the maternal uterus, it has no effect on adhesion of uterine stroma (Julian et al. 1994). Tenascin gene expression is regulated by the TRE/ AP-1 promoter element, which also serves to mediate responsiveness to growth factor signals (Edelman and Jones 1993). Consistent with our results involving the outgrowth of blastocysts under different growth conditions (data not shown), evx1 protein has been shown to substitute for the high serum conditions required for high levels of expression with the TRE/AP-1 promoter element (Edelman and Jones 1993). This is interesting considering that peptide growth factors have been implicated in the regulation of even-skipped gene expression (Altaba and Melton 1989; Grueneberg et al. 1992; Niswander and Martin 1993). Thus, the inadequate function of critical growth factors resulting from disruption of $e v x 1$ could provide an explanation for the mutant phenotype.

In summary, initial evx1 expression studies suggested that the first critical function of this gene during development might involve initiating the process of gastrulation (Bastian and Gruss 1990; Dush and Martin 1992). Genetic analysis has demonstrated that evx1 plays a critical role after implantation but before egg cylinder formation and the onset of gastrulation. Other kinds of mutations that target the evx1 regulatory elements or place this gene under conditional control may allow evaluation of later developmental functions associated with this critical gene.

\section{Materials and methods}

Preparation of targeting vector

A $\lambda$-genomic DNA library was screened with a 430-bp BamHIPstI, homeo box-containing fragment derived from the Xenopus even-skipped cDNA plasmid pcXhox-3 (kindly provided by D. Melton; Altaba and Melton 1989). DNA sequence analysis showed that the phage clones obtained contained the mouse evx1 gene (Bastian and Gruss 1990). A 10.2-kb XbaI fragment containing the entire mouse $e v x 1$ gene was subcloned from purified phage into pUC19. evx1 homeo box sequences located between the SmaI site in exon 2 and the XhoI site in intron 2 were replaced with a $1.1-\mathrm{kb}$ SmaI-SalI MC1NEOpA cassette (Thomas and Capecchi 1987). From this plasmid a 10.0-kb SalI$X b a I$ fragment was ligated into a SalI-SpeI-digested Bluescript KS + vector (Stratagene) containing the HSV TK genes 1 and 2 (Chisaka and Capechi 1991). The resulting targeting vector, $\mathrm{p} E v x 1 \mathrm{neo2TK}$, was amplified, $\mathrm{CsCl}$ purified, and linearized with either XhoI or ScaI prior to introduction into ES cells (Fig. 2a). 


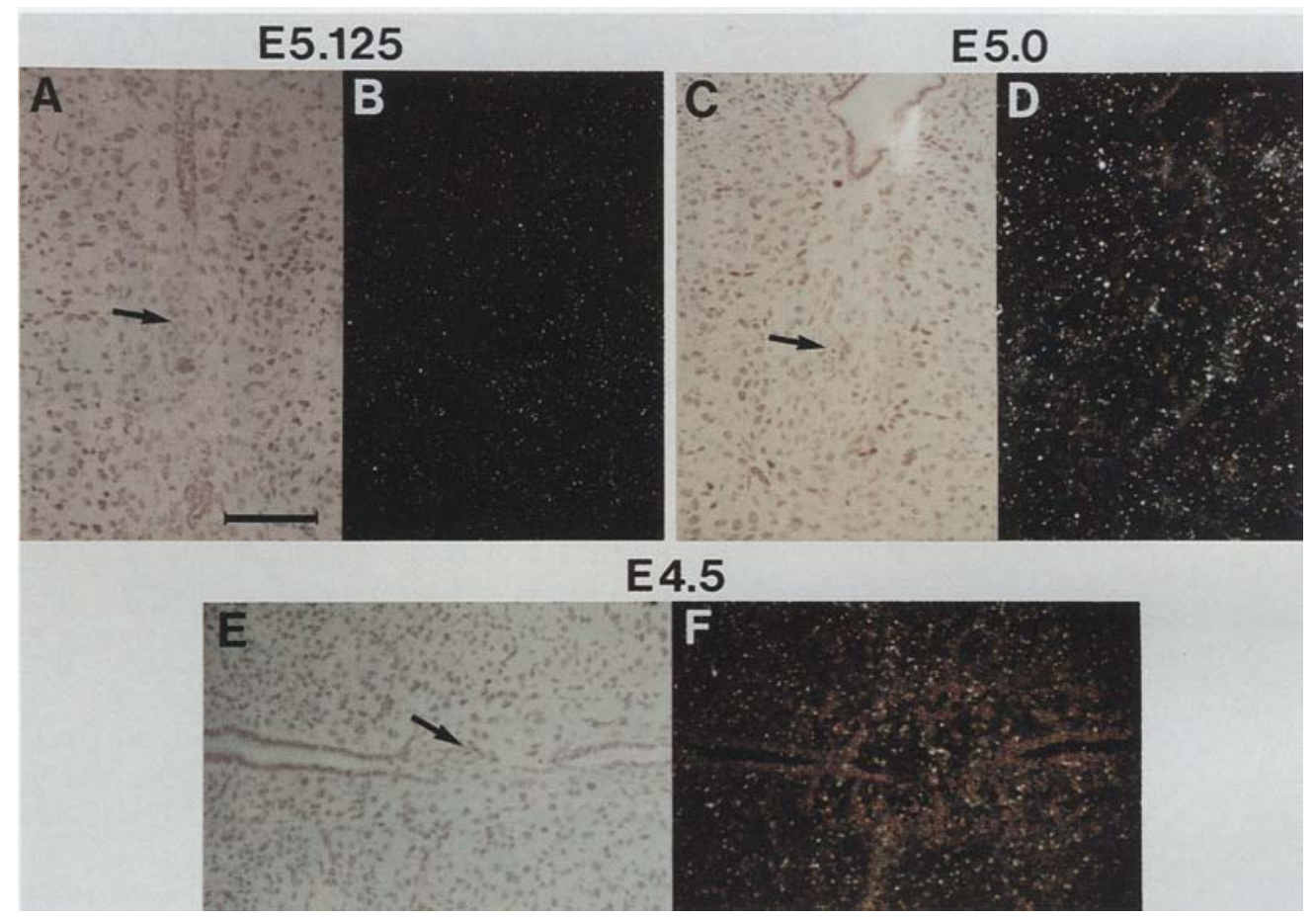

Figure 9. In situ hybridization of presumptive homozygous evx1 $1^{-} / e v x 1^{-}$embryos in uterine sections. The uteri of C57BL/6J females were isolated 4.5-6.5 days after a 2-hr mating with C57BL/6J males, and $8 \mu \mathrm{m}$ sections were prepared for in situ hybridization. $(A, B)$ E5.125 embryo; $(C, D)$ E5.0 embryo; $(E, F)$ E4.5 embryo. $\{A, C, E)$ bright-field images; $(B, D, F)$ dark-field images. Sections of wild-type E6.5 embryos were included as positive controls. Arrows indicate the location of the implanted blastocysts. Bar, $100 \mu \mathrm{m}$.

\section{Generation of targeted cell lines}

DNA was introduced into ES cells by electroporation as described by Deng and Capecchi (1992). A total of $86 \mu \mathrm{g}$ of XhoIor ScaI-linearized $\mathrm{pEvx} 1$ neo2TK was electroporated into $2 \times 10^{7}$ CCl.2 ES cells in EP buffer $20 \mathrm{~mm}$ HEPES at pH 7.0, $6 \mathrm{~mm}$ dextrose, $137 \mathrm{~mm} \mathrm{NaCl}, 5 \mathrm{~mm} \mathrm{KCl}, 0.7 \mathrm{mM} \mathrm{Na} \mathrm{HPO}_{4}, 2 \mathrm{~mm}$ $\beta$-mercaptoethanol) at a concentration of $10^{7} \mathrm{cells} / \mathrm{ml}$ per reaction, with two bursts at $625-650 \mathrm{~V} / \mathrm{cm}$ at room temperature by use of the Promega Biotech X Cell 2000. After electroporation $\sim 10^{6}$ ES cells were plated per $10-\mathrm{cm}$ dish seeded with mitomycin-treated Neo Sto cells in $15 \mathrm{ml}$ of DMEM containing $10 \%$ heat-inactivated FCS and $500 \mathrm{IU} / \mathrm{ml}$ of LIF. ES cells were subsequently subjected to 8 days of selection with the above media supplemented with $230 \mu \mathrm{g} / \mathrm{ml}$ of G418 and $1.25 \mu \mathrm{M}$ FIAU (Mansour et al. 1988). ES cells were subsequently selected for 2 days in media supplemented with $230 \mu \mathrm{g} / \mathrm{ml}$ of G418, picked, trypsinized, and placed into wells seeded with mitomycintreated Neo Sto cells in media containing $187 \mu \mathrm{g} / \mathrm{ml}$ of G418. After they had grown into large colonies, they were transferred to $60-\mathrm{mm}$ dishes seeded with mitomycin-treated Sto cells in media without selection. When colonies covered $\sim 80 \%$ of the dish, they were removed with trypsin and two-thirds of the sample frozen in freezing medium (Hogan et al. 1986), whereas the remaining one-third was placed in cell lysis buffer $(20 \mathrm{mM}$ Tris at $\mathrm{pH} 7.5,10 \mathrm{~mm}$ EDTA, $100 \mathrm{~mm} \mathrm{NaCl}, 0.5 \%$ SDS) for later DNA analysis.

\section{Identification of $\mathrm{evx}^{-} / \mathrm{evx1} 1^{+}$cell lines}

DNA from 95 ES cell lines was analyzed for the replacement of one of the cognate evx1 alleles. ES cells in cell lysis buffer were first digested with $0.2 \mathrm{mg} / \mathrm{ml}$ of proteinase $\mathrm{K}$ at $37^{\circ} \mathrm{C}$ for $4 \mathrm{hr}$, followed by a phenol extraction, a chloroform extraction, and precipitation by addition of $7.5 \mathrm{M}$ ammonium acetate and isopropanol. The DNA was spooled and resuspended in $10 \mathrm{~mm}$ Tris- $\mathrm{HCl}, 1 \mathrm{~mm}$ EDTA. The targeted cell lines used to generate the reported mice were analyzed extensively by Southern transfer hybridization with a variety of restriction enzymes, and both flanking and internal probes (Fig. 2). Hybridization probes were labeled with $\left[{ }^{32} \mathrm{P}\right] \mathrm{dCTP}$ by random priming (Sambrook et al. 1989). Flanking probe A, an 880-bp SalI-SmaI fragment, was used to hybridize with ES cell DNA that was digested with EcoRV, size separated, and transferred onto nitrocellulose (Fig. $2 \mathrm{c}, \mathrm{d})$. Probe A hybridizes to 20 - and $1.5-\mathrm{kb}$ EcoRV restriction fragments from wild-type genomes (Fig. 2c,d, lane 777.4). When one allele of the evx1 gene is replaced with targeting vector sequences by homologous recombination, an additional hybridizing 3.1-kb EcoRV restriction fragment appears (Fig. 2c,d, lanes 777.5-777.7). Of 95 G418/FIAU-resistant cell lines, four had undergone the homologous recombination event (Fig. 2b,c). An internal Neo probe (768-bp EagI-BamHI fragment from the coding region of the neomycin phosphotransferase gene) was used to hybridize with DNA that was digested with Asp718, BgIII, and $B a m H I$, size separated and transferred onto nitrocellulose (Fig. 2b,c). The integrity of homologous recombinants was demonstrated by the appearance of single bands at $5.9 \mathrm{~kb}$ for $A s p 718$, $7.6 \mathrm{~kb}$ for BglII, and $6.7 \mathrm{~kb}$ for BamHI (Fig. 2b,c).

\section{Breeding and genotypic analysis of offspring}

The 4e-4 ES cell line was used for injection into C57BL/6J blastocysts, and the resulting male chimeras were test bred to nonagouti C57BL/6J females (Jackson Laboratories). One of these 
chimeric males, number 777 , transmitted the agouti coat color, which is characteristic of the mice from which the 129-strain ES line was derived, to $6 \%$ of his progeny (Fig. $2 \mathrm{~d}$, left). The $e v \times 1^{-}$/ evx $1^{+}$heterozygous colony produced by chimera number 777 was expanded by crossing to C57BL/6J mice. Intercross litters were obtained by pairing male and female evx1-/evx $1^{+}$heterozygotes for $2 \mathrm{hr}$ early in the morning and then checking for plugs. DNA was prepared from yolk sacs of embryos or tails of pups by phenol and chloroform extraction of proteinase K-digested samples as described previously (Hogan et al. 1986; Mansour et al. 1993). DNA samples were digested with EcoRV and hybridized to probe A as described above (Fig. 2c,d), or digested with Asp718 and hybridized with internal probe C la 670-bp PvuII-Xhol DNA fragment from evx1 exon 2; Fig. 2c,d, right panels). By this latter approach, a $4.8-\mathrm{kb}$ hybridizing band was produced by the wild-type $e v x 1$ allele and a $5.9-\mathrm{kb}$ hybridizing band was produced by the mutant $e v x 1^{-}$allele (Fig. 2c,d, right panels).

\section{PCR analysis of $\mathrm{evx} 1^{-} / \mathrm{evx} 1^{+}$intercross embryos}

DNA from tails, yolk sacs, egg cylinders, and blastocysts was prepared and analyzed by PCR as described by McMahon and Bradley (1990) with a few modifications. Briefly, cells were lysed at $55^{\circ} \mathrm{C}$ in $20-100 \mu \mathrm{l}$ of PCR lysis buffer $(50 \mathrm{~mm} \mathrm{KCl}, 1.5 \mathrm{~mm}$ $\mathrm{MgCl}_{2}, 10 \mathrm{~mm}$ Tris- $\mathrm{HCl}$ at $\mathrm{pH} 8.5,0.01 \%$ gelatin, $0.45 \% \mathrm{NP}-40$, $0.45 \%$ Tween 20 , and $100 \mu \mathrm{g} / \mathrm{ml}$ of proteinase $\mathrm{K}$ ) for $4-16 \mathrm{hr}$. The proteinase $\mathrm{K}$ was inactivated by incubation at $95^{\circ} \mathrm{C}$ for 5 min just prior to PCR analysis. PCR was carried out in $12.5-\mu l$ reactions containing $50 \mathrm{mM} \mathrm{KCl}, 1.5 \mathrm{mM} \mathrm{MgCl}_{2}, 10 \mathrm{~mm}$ Tris$\mathrm{HCl}(\mathrm{pH} 8.5), 0.01 \%$ gelatin, $250 \mu \mathrm{M}$ of the four dNTPs, $100 \mathrm{ng}$ of each primer, 0.5 units of Taq polymerase (Promega), and $1 \mu \mathrm{l}$ of heat-inactivated lysis buffer containing the DNA sample. DNA samples from tails and yolk sacs were amplified for 32 cycles and DNA samples from egg cylinders and blastocysts were amplified for 38 cycles of denaturation for $1 \mathrm{~min}$ at $94^{\circ} \mathrm{C}$, annealing for $1 \mathrm{~min}$ at $63^{\circ} \mathrm{C}$, and elongation for $30 \mathrm{sec}$ plus 1 sec/cycle at $72^{\circ} \mathrm{C}$ under light topical mineral oil. The resulting PCR products $(6 \mu)$ were resolved on $12 \%$ acrylamide $(30: 0.8)$ gels at $170 \mathrm{~V}$ for $1 \mathrm{hr}$ and visualized with UV light after staining with ethidium bromide. A mixture of three PCR primers was used to detect wild-type and mutant alleles: forward evx1 primer,

5'-AGTGACCAGATGCGCCGATACCGC-3'; reverse evx1 primer, 5'-CCTTGATGGTAGTTTCAGGAAGG-3'; and reverse NEO primer, $5^{\prime}$-CGTGTTCGAATTCGCCAATGACAAGAC-3'.

\section{In vitro culture of blastocyst outgrowths}

Intercross blastocysts were generated by pairing male and female $e v \times 1^{-} / e v x 1^{+}$heterozygotes for $2 \mathrm{hr}$ early in the light cycle and checking females for plugs. Blastocysts were isolated from females at E4.0 as described previously (Hogan et al. 1986) with Dulbecco's modified Eagle medium (DMEM) supplemented with $10 \%$ FCS. E4.0 hatched blastocysts were preferred to E3.5 blastocysts because it was determined that the hatched blastocysts grew more synchronously than the younger unhatched blastocysts. Blastocysts were grown on $35-\mathrm{mm}$ dishes (Falcon) in CMRL1066 medium supplemented with 15\% FCS, 1 mM L-glutamine, and $1 \mathrm{~mm}$ sodium pyruvate for 3-5 days at $37^{\circ} \mathrm{C}$ in a $5 \% \mathrm{CO}_{2}$ incubator as described by Wu et al. (1981) and Gonda and $\mathrm{Hsu}$ (1980).

\section{Preparation of histological sections}

Uteri from females plugged in a 2 -hr mating period were isolated in ice-cold phosphate buffered saline (PBS) at E4.5 or later, pinned to syringe plungers, fixed in fresh $4 \%$ paraformaldehyde/ PBS (or in Bouin's fixative) at $4^{\circ} \mathrm{C}$ overnight, dehydrated through a graded ethanol series, cleared in xylene, and then infiltrated and embedded in Paraplast X-tra (Polysciences). Bouin's fixed specimens were also transferred through three changes of $5 \%$ sucrose, $10 \mathrm{~mm}$ sodium phosphate $(\mathrm{pH} 8.0)$ at $4^{\circ} \mathrm{C}$ prior to dehydration. Sections $(8 \mu \mathrm{m})$ were collected on acidtreated slides and stained regressively with Harris' hematoxylin/eosin and mounted in DPX (Aldrich). All sections of excised uterine horns were cut in transverse orientation according to the nomenclature of Smith (1985).

\section{In situ hybridization}

In situ hybridizations were performed as described by Frohman et al. (1990) with a few modifications. Briefly, uteri from females plugged in a 2 -hr mating period were isolated in ice-cold PBS at E4.5 or later, fixed at $4^{\circ} \mathrm{C}$ overnight in fresh $4 \%$ paraformaldehyde/PBS $(\mathrm{pH} 8.0)$, dehydrated through a graded ethanol series, cleared in xylene, and infiltrated and embedded in Paraplast X-tra (Polysciences). Sections $(8 \mu \mathrm{m})$ were cut, dried onto poly-L-lysine-coated slides, treated with $20 \mu \mathrm{g} / \mathrm{ml}$ of proteinase $\mathrm{K}$, and acetylated. Hybridization was carried out overnight at $55^{\circ} \mathrm{C}$ in a solution containing $50 \%$ formamide, $0.3 \mathrm{M} \mathrm{NaCl}, 20$ mM Tris- $\mathrm{HCl}$ (pH 8.0), $5 \mathrm{~mm}$ EDTA, $10 \mathrm{~mm}$ sodium phosphate (pH 8.0 ), $10 \%$ dextran sulfate, $1 \times$ Denhardt's solution, $500 \mu \mathrm{g} /$ $\mathrm{ml}$ of yeast tRNA, $10 \mathrm{~mm}$ DTT, and $\sim 2 \times 10^{5} \mathrm{dpm}$ of probe $/ \mu \mathrm{l}$ (sp. act. $\sim 10^{9} \cdot \mathrm{dpm} \cdot \mu \mathrm{g} \mathrm{RNA}^{-33} \mathrm{P}$ ). Probe labeled with ${ }^{33} \mathrm{P}$ was used because of the low levels of evx1 gene expression detectable within younger embryos (Figs. $7 \mathrm{D}, \mathrm{F}$ and 8 ) and the background produced using ${ }^{35} \mathrm{~S}$-labeled anti-sense probe. Slides were washed for $30 \mathrm{~min}$ at high stringency in $50 \%$ formamide, $2 \times$ SSC, $0.1 \mathrm{M} \mathrm{DTT}$ at $65^{\circ} \mathrm{C}$, followed by three washes in $0.5 \mathrm{M}$ $\mathrm{NaCl}, 10 \mathrm{~mm}$ Tris- $\mathrm{HCl}, 5 \mathrm{~mm}$ EDTA (NTE) for $10 \mathrm{~min}$ at $37^{\circ} \mathrm{C}$, one wash in NTE containing $20 \mu \mathrm{g} / \mathrm{ml}$ of RNase $A$ for $1 \mathrm{hr}$ at $37^{\circ} \mathrm{C}$, and one wash in NTE for $15 \mathrm{~min}$ at $37^{\circ} \mathrm{C}$. A second high stringency wash was performed and was followed by $15-\mathrm{min}$ washes in $2 \times \mathrm{SSC}$ and $0.1 \times \mathrm{SSC}$ at $37^{\circ} \mathrm{C}$. Slides were dehydrated, dipped in Kodak NTB-2 emulsion diluted $1: 1$ with $0.6 \mathrm{M}$ ammonium acetate, and exposed for $2-4$ weeks at $4^{\circ} \mathrm{C}$. Slides were developed, stained with Mayer's hematoxylin (Sigma) and eosin, and mounted in DPX (Aldrich). A Bluescript KS + plasmid (Stratagene) containing the 436-bp BamHI-KpnI 3'-untranslated $e v x 1$ gene fragment was linearized with BamHI or $K p n I$ and used in conjunction with T3 or T7 RNA polymerases to produce antisense and sense riboprobes, respectively. Hybridization using the evx1 sense strand was included as a negative control, demonstrating no specific hybridization at any of the stages studied (data not shown). Sections of wild-type E6.5 embryos were included as positive controls (Fig. 7A,B).

\section{Acknowledgments}

We thank M. Allen, S. Barnett, C. Lenz, E. Nakashima, and S. Tamowski for excellent technical assistance, R. Carter for help with statistical analysis, and L. Oswald for help with preparation of the manuscript. D.D.S. was supported by a Jane Coffin Childs Memorial Fund post-doctoral fellowship and a Howard Hughes Medical Institute appointment during the course of this work.

The publication costs of this article were defrayed in part by payment of page charges. This article must therefore be hereby marked "advertisement" in accordance with 18 USC section 1734 solely to indicate this fact. 


\section{References}

Altaba, A.R.I. and D.A. Melton. 1989. Interaction between peptide growth factors and homeobox genes in the establishment of antero-posterior polarity in frog embryos. Nature 341: 33-38.

Axelrod, H.R. 1985. Altered trophoblast functions in implantation-defective mouse embryos. Dev. Biol. 108: 185-190.

Bastian, H. and P. Gruss. 1990. A murine even-skipped homologue, Evx1, is expressed during early embryogenesis and neurogenesis in a biphasic manner. EMBO J. 9: 1839-1852.

Bennett, D. 1975. The T-locus of the mouse. Cell 6: 441-454.

Capecchi, M.R. 1989. Altering the genome by homologous recombination. Science 244: 1288-1292.

1994. Targeted gene replacement. Sci. Am. 270: 54-61.

Casanova, J.E. and L.B. Grabel. 1988. The role of cell interactions in the differentiation of teratocarcimona-derived parietal and visceral endoderm. Dev. Biol. 129: 124-139.

Chisaka, O. and M.R. Capecchi. 1991. Regionally restricted developmental defects resulting from targeted disruption of the mouse homeobox gene hox-1.5. Nature 350: 473-479.

Copp, A.J. 1979. Interaction between inner cell mass and trophectoderm of the mouse blastocyst. II. The fate of the polar trophectoderm. J. Embryol. Exp. Morphol. 51: 109-120.

DeGregori, J., A. Russ, H. von Melchner, H. Rayburn, P. Priyaranjan, N.A. Jenkins, N.G. Copeland, and H.E. Ruley. 1994. A murine homolog of the yeast RNAl gene is required for postimplantation development. Genes \& Dev. 8: 265276.

Deng, C. and M.R. Capecchi. 1992. Reexamination of gene targeting frequency as a function of the extent of homology between the targeting vector and the target locus. Mol. Cell. Biol. 12: 3365-3371.

Dush, M.K. and G.R. Martin. 1992. Analysis of mouse EvX genes: Evx-1 displays graded expression in the primitive streak. Dev. Biol. 151: 273-287.

Eaton, G.J. and M.M. Green. 1963. Giant cell differentiation and lethality of homozygous YELLOW mouse embryos. Genetica 34: 155-161.

Edelman, G.M. and F.S. Jones. 1993. Outside and downstream of the homeobox. J. Biol. Chem. 268: 20683-20686.

Erickson, R.P. and R.A. Pedersen. 1975. In vitro development of $t^{6} / t^{6}$ embryos. I. Exp. Zool. 193: 377-384.

Frohman, M.A., M. Boyle, and G.R. Martin. 1990. Isolation of the mouse Hox-2.9 gene; analysis of embryonic expression suggests that positional information along the anterior-posterior axis is specified by mesoderm. Development 110: $589-607$.

Gardner, R.L. 1983. Origin and differentiation of extraembryonic tissues in the mouse. Int. Rev. Exp. Pathol. 24: 63-133.

Gardner, R.L. and V.E. Papaioannou. 1975. Differentiation in the trophectoderm and inner cell mass. In The early development of mammals, Second Symposium of the British Society for Developmental Biology (ed. M. Balls and A.E. Wild), pp. 107-132. Cambridge University Press, Cambridge, UK.

Gluecksohn-Schoenheimer, S. 1940. The effect of an early lethal $\left(t^{\circ}\right)$ in the house mouse. Genetics 25: 391-400.

Golbus, M.S., P.G. Calarco, and C.J. Epstein. 1973. The effect of inhibitors of RNA synthesis (alpha-amanitin and actinomycin D) on preimplantation mouse embyrogenesis. J. Exp. Zool. 186: 207-216.

Gonda, M.A. and Y.-C. Hsu. 1980. Correlative scanning electron, transmission electron, and light microscopic studies of the in vitro development of mouse embryos on a plastic substrate at the implantation stage. I. Embryol. Exp. Morphol. 56: 23-39.
Grueneberg, D.A., S. Natesan, C. Alexandre, and M. Gilman. 1992. Human and Drosophila homeodomain proteins that enhance the DNA-binding activity of serum response factor. Science 257: 1089-1095.

Hogan, B.L.M. and R. Tilly. 1981. Cell interactions and endoderm differentiation in cultured mouse embryos. I. Embryol. Exp. Morph. 62: 379-394.

Hogan, B., F. Costantini, and E. Lacy. 1986. Manipulating the mouse embryo. Cold Spring Harbor Laboratory, Cold Spring Harbor, New York.

Jones, F.S., G. Chalepakis, P. Gruss, and G.M. Edelman. 1992. Activation of the cytotactin promoter by the homeobox-containing gene Evx1. Proc. Natl. Acad. Sci. 89: 2091-2095.

Julian, J., R. Chiquet-Ehrismann, H.P. Erickson, and D.D. Carson. 1994. Tenascin is induced at implantation sites in the mouse uterus and interferes with epithelial cell adhesion. Development 120: 661-671.

Lewis, S.E., H.A. Turchin, and S. Gluecksohn-Waelsch. 1976. The developmental analysis of an embryonic lethal $\left(c^{6 H}\right)$ in the mouse. J. Embryol. Exp. Morphol. 36: 363-371.

Mansour, S.L., K.R. Thomas, and M.R. Capecchi. 1988. Disruption of the proto-oncogene int-2 in mouse embryo-derived stem cells: A general strategy for targeting mutations to nonselectable genes. Nature 336: 348-352.

Mansour, S.L., J.M. Goddard, and M.R. Capecchi. 1993. Mice homozygous for a targeted disruption of the proto-oncogene int-2 have developmental defects in the tail and inner ear. Development 117: 13-28.

McLaren, A. 1976. Genetics of the early mouse embryo. Annu. Rev. Genet. 10: 361-388.

McMahon, A. and A. Bradley. 1990. The Wnt-1 (int-1) protooncogene is required for development of a large region of the mouse brain. Cell 62: 1073-1085.

Michaud, E.J., S.J. Bultman, L.J. Stubbs, and R.P. Woychik. 1993. The embryonic lethality of homozygous lethal yellow mice $\left(A^{y} / A^{y}\right)$ is associated with the disruption of a novel RNAbinding protein. Genes \& Dev. 7: 1203-1213.

Niswander, L. and G.R. Martin. 1993. FGF-4 regulates expression of EvX1 in the developing mouse limb. Development 119: 287-294.

Otting, G., Y. Qian, M. Müller, M. Affolter, W. Gehring, and K. Wüthrich. 1988. Secondary structure determination for the Antennapedia homeodomain by nuclear magnetic resonance and evidence for a helix-turn-helix motif. EMBO /. 7: 4305-4309.

Papaioannou, V. and R.L. Gardner. 1979. Investigation of the lethal yellow $A^{y} / A^{y}$ embryo using mouse chimaeras. J. Embryol. Exp. Morphol. 52: 153-163.

Pederson, R.A. and A.I. Spindle. 1976. Genetic effects on mammalian development during and after implantation. Embryogenesis in mammals. Ciba Found. Symp. 40: 133-146.

Rossant, J. and K.M. Vijh. 1981. In vivo and in vitro development of mouse embryos homozygous for the embryonic lethal velvet coat (Ve) mutation. J. Embryol. Exp. Morphol. 66: 43-55.

Rowinski, J., D. Solter, and H. Koprowski. 1975. Mouse embryos development in vitro: Effects of inhibitors of RNA and protein synthesis on blastocyst and post-blastocyst embryos. J. Exp. Zool. 192: 133-142.

Saga, Y., T. Yagi, Y. Ikawa, T. Sakakura, and S. Aizawa. 1992. Mice develop normally without tenascin. Genes \& Dev. 6: 1821-1831.

Sambrook, J., E.F. Fritsch, and T. Maniatis. 1989. Molecular cloning: A laboratory manual. Cold Spring Harbor Laboratory Press, Cold Spring Harbor, New York.

Sherman, M.I. and S.B. Atienza. 1975. Effects of bromodeoxyu- 
ridine, cytosine arabinoside, and colcemid upon in vitro development of mouse blastocysts. J. Embryol. Exp. Morphol. 34: 467-484.

Smith, L.J. 1985. Embryonic axis orientation in the mouse and its correlation with blastocyst relationships to the uterus II. Relationship from $41 / 4$ to 9 1/2 days. J. Embryol. Exp. Morphol. 89: 15-35.

Snow, M.H.L. 1973. Abnormal development of pre-implantation mouse embryos grown in vitro with ${ }^{3} \mathrm{H}$-thymidine. $I$. Embryol. Exp. Morphol. 29: 601-615.

- 1976. Embryo growth during the immediate postimplantation period. Embryogenesis in mammals. Ciba Found. Symp. 40: 53-70.

Soriano, P., T. Gridley, and R. Jaenisch. 1987. Retrovinuses and insertional mutagenesis in mice: Proviral integration at the Mov34 locus leads to early embryonic death. Genes \& Dev. 1: 366-375.

Spiegelman, M., K. Artzt, and D. Bennett. 1976. Embryological study of a $T / t$ locus mutation $\left(t^{w 73}\right)$ affecting trophectoderm development. J. Embryol. Exp. Morphol. 36: 373-381.

Strickland, S. and W.G. Richards. 1992. Invasion of the trophoblasts. Cell 71: 355-357.

Thomas, K.R. and M.R. Capecchi. 1987. Site-directed mutagenesis by gene targeting in mouse embryo-derived stem cells. Cell 51: 503-512.

Vankin, G.L. and E.W. Caspari. 1979. Developmental studies of the lethal gene Bld in the mouse. I. Post-implantation development of the lethal homozygote. J. Embryol. Exp. Morphol. 49: 1-12.

Wu, T.-C., Y.-J. Wan, and I. Damjanov. 1981. Positioning of inner cell mass determines the development of mouse blastocysts in vitro. J. Embryol. Exp. Morphol. 65: 105-117. 


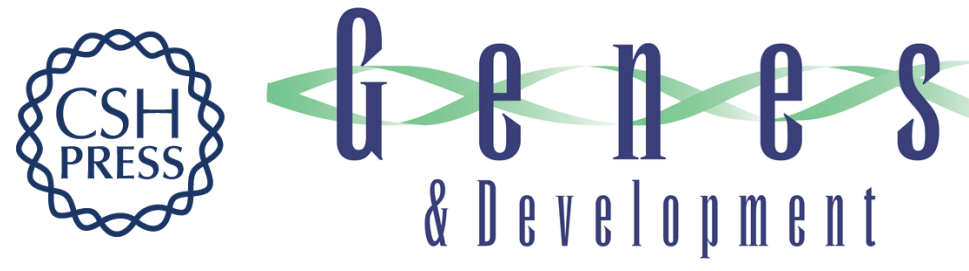

\section{Targeted disruption of the even-skipped gene, evx1, causes early postimplantation lethality of the mouse conceptus.}

D D Spyropoulos and M R Capecchi

Genes Dev. 1994, 8:

Access the most recent version at doi:10.1101/gad.8.16.1949

References This article cites 47 articles, 14 of which can be accessed free at:

http://genesdev.cshlp.org/content/8/16/1949.full.html\#ref-list-1

License

Email Alerting

Service

Receive free email alerts when new articles cite this article - sign up in the box at the top right corner of the article or click here.

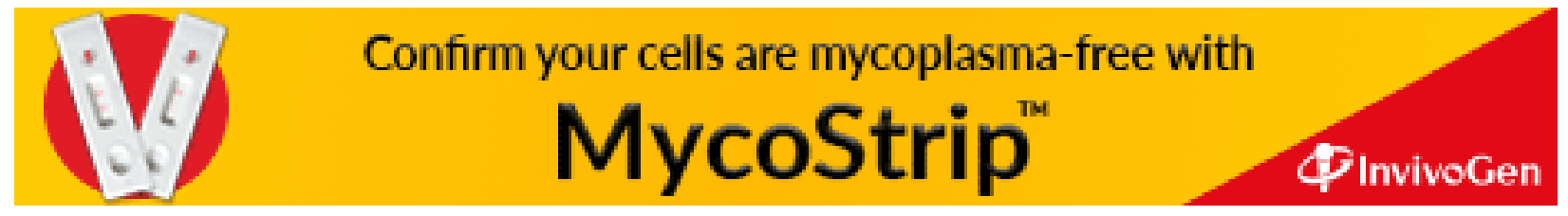

